\title{
A Method for Rapid Demineralization of Teeth and Bones
}

\author{
Andrew Cho ${ }^{1}$, Shigeki Suzuki ${ }^{1}$, Junko Hatakeyama ${ }^{1}$, Naoto Haruyama ${ }^{1}$, and Ashok B. Kulkarni ${ }^{1.2, *}$ \\ ${ }^{1}$ Gene Targeting Facility, and ${ }^{2}$ Functional Genomics Section, Laboratory of Cell and Developmental Biology, National \\ Institute of Dental and Craniofacial Research, National Institutes of Health, 30 Convent Drive, Bethesda, MD 20892, \\ USA
}

\begin{abstract}
Tooth and bone specimen require extensive demineralization for careful analysis of cell morphology, as well as gene and protein expression levels. The LacZ gene, which encodes the B-galactosidase enzyme, is often used as a reporter gene to study gene-structure function, tissue-specific expression by a promoter, cell lineage and fate. This reporter gene is particularly useful for analyzing the spatial and temporal gene expression pattern, by expressing the LacZ gene under the control of a promoter of interest. To analyze LacZ activity, and the expression of other genes and their protein products in teeth and bones, it is necessary to carry out a complete demineralization of the specimen before cutting sections. However, strong acids, such as formic acid used for tooth demineralization, destroy the activities of enzymes including those of $\beta-$ galactosidase. Therefore, most protocols currently use mild acids such as $0.1 \mathrm{M}$ ethylene diamine tetra-acetic acid (EDTA) for demineralization of tooth and bone specimen, which require a longer period of treatment for complete demineralization. A method by which hard tissue specimens such as teeth and bones can be rapidly, but gently, decalcified is necessary to save time and effort. Here, we report a suitable method for rapid demineralization of mouse teeth in $0.1 \mathrm{M}$ EDTA at $42^{\circ} \mathrm{C}$ without any loss of $\beta$-galactosidase activity.
\end{abstract}

Key Words: Demineralization, tooth, LacZ, gene expression

\section{INTRODUCTION}

Teeth are the hardest tissues in the body, consisting of enamel, dentin, and cementum, and have a highly mineralized extracellular matrix. Unlike soft tissues, which can be easily sectioned and analyzed, teeth require complete demineralization in order to prepare proper sections for histological analysis using certain stains and antibodies. In the past, many decalcifiers have been tested for different purposes. For example, the Morse's solution, a strong acid baseddecalcifier, has been used for the rapid detection of RNA by in-situ hybridization (ISH) [1]. Another acid-based solution, 5\% trichloroacetic acid (TCA), has been used for the analysis of DNA strand breaks by terminal deoxy (d)-UTP nickend labeling (Tunnel) [2]. EDTA containing solution is a mild demineralization agent which has been mostly used for immunolocalization studies because of its antigen-preserving properties. Treatment of bones with 0.1 M EDTA following initial fixation in glutaraldehyde has been reported as adequate for immunocytochemical localization of certain bone matrix proteins [3]. Furthermore, the treatment of dental tissues with $4.3 \%$ EDTA resulted in satisfactory preservation of the fine structures of the cells and matrices [4], however it requires a relatively long incubation time in order to achieve complete demineralization [5,6]. For example, to demineralize human deciduous teeth for analysis, it requires 4 weeks of demineralization using 10\% EDTA [7]. To demineralize a 1-month-old mouse skull with similar EDTA solution it takes about 3-4 weeks of treatment to prepare the specimen for analyzing expression levels of the LacZ and growth fac

*Address correspondence to this author at the Chief, FGS, CDBRB, NIDCR, NIH, Tel: 301-435-2887; Fax: 301-435-288;

E-mail: ak40m@nih.gov tor genes [8,9]. To achieve fast demineralization, a microwave-induced demineralization method has been examined $[10,11]$. While this method has achieved faster demineralization time compared to the traditional method, preserved the fine morphological structures of the bone tissue, and retained RNA, its effect on LacZ gene expression has not been addressed. Moreover it has been speculated that the advantages associated with using the method are due to the higher temperature attained during microwaving the specimen purely due to thermal effect [12].

The LacZ gene is widely used to investigate promoter activity [13-15], however there is not detailed protocol for optimal analysis of $B$-galactosidase activity in decalcified mouse teeth and bones. Moreover, the effects of acid-based decalcifiers and different fixatives used for preparation of mouse teeth specimen to analyze $\beta$-galactosidase activity have not been well established. In this report, we demonstrate the effects of several fixatives and decalcifiers on mouse teeth specimen for LacZ activity, whose expression is driven by a tooth specific DSPP (Dentin Sialophophoprotein) promoter. Most importantly, we have explored the effects of elevated temperatures on mouse teeth specimen to optimize a rapid but gentle demineralization method suitable for analysis of LacZ activity. This will prove to be a suitable method for rapid demineralization of mouse skulls for analysis using histochemical staining and in-situ hybridization.

\section{MATERIALS \& METHODS}

Experimental Animals: We reported earlier on the generation and characterization of the Dspp-LacZ transgenic mice, which express LacZ predominantly in the odontoblasts, were used for all the experiments in this study [16]. The skulls from 2-week-old, 1-month-old, 3-month-old, and 
1-year-old mice were removed after cervical dislocation and were cut into two symmetrical halves. The mouse skulls were subsequently treated using the indicated procedures. Studies were performed in compliance with the National Institutes of Health (NIH) guidelines on the care and use of laboratory and experimental animals. All experimental procedures were approved by the Animal Care and Use Committee of the National Institute of Dental and Craniofacial Research.

Genotyping: Genotyping was performed by PCR analysis of genomic DNA extracted from tail snips. Tail biopsies were lysed overnight at $55^{\circ} \mathrm{C}$ in a lysis buffer containing $100 \mathrm{mM}$ Tris pH7.4, 5mM EDTA, 200mM NaCl, 0.2\% SDS, and $100 \mu \mathrm{g} / \mathrm{ml}$ Proteinase $\mathrm{K} / \mathrm{ml}$ (Invitrogen) in distilled water. DNA was purified using phenol and chloroform, and PCR was performed for genotyping Dspp-LacZ transgenic mice using the following primers: the forward primer (5'CGTAATAGCGAAGAGGCCCGCACC-3') and the reverse primer (5'-CCTGCGTTTCACCC TGCCATAAAG-3). The PCR conditions were set as follows: 30 cycles at $94^{\circ} \mathrm{C}$ for 1 min., $70^{\circ} \mathrm{C}$ for $30 \mathrm{sec}$, and $72^{\circ} \mathrm{C}$ for $1 \mathrm{~min}$.

B-galactosidase Assay: The skulls were cut from 3month-old Dspp-LacZ transgenic mice, and skins were removed and then fixed with $0.25 \%$ glutaraldehyde in PBS, $4 \%$ paraformaldehyde (PFA) in PBS, aqueous buffered zinc formalin (Anatech Ltd, Battle Creek, MI), or 10\% formalin, for 1 hour at room temperature, and decalcified in $0.1 \mathrm{M}$ EDTA (0.5M EDTA, pH 8.0 buffered by 1 X DPBS, pH 7.5) for 3 weeks. Decalcified skulls were then washed in PBS three times and embedded overnight in O.C.T. compound (Sakura, Torrance, CA) to prepare frozen sections for cutting. Next day, the sections that were $12 \mu \mathrm{m}$ in thickness were cut using Cryostat (Leica Microscopy, model CM3050 $\mathrm{S}$ ), and transferred onto Vectobond treated slides (Vector Laboratories, Burlingame, CA). These sections were stained with LacZ solution containing $0.02 \%$ NP-40 (IPEGAL), $0.01 \%$ sodium deoxycholate, $2 \mathrm{mM} \mathrm{MgCl}_{2}, 1 \mathrm{mM}$ spermidine, $5 \mathrm{mM}$ potassium ferricyanide, $5 \mathrm{mM}$ potassium ferrocyanide, and $0.5 \mathrm{mg} / \mathrm{ml}$ bluo-Gal (Invitrogen, Carlsbad, CA) in phosphate buffered saline (PBS) overnight at $37^{\circ} \mathrm{C}$. The stained sections were counterstained with eosin and then photographed (Axioplan 2, Zeiss, Thornwood, NY).

Post Fixation Assay: The skulls were cut from 3-monthold mice, fixed, decalcified, and sections were arranged on the slides as described above. The slides containing tooth incisor sections were post-fixed with $4 \%$ PFA for 0 min., 2 min., 5 min., 10 min., $30 \mathrm{~min}$., and 2 hours at RT, before being stained with LacZ solution as described above.

Decalcifier Comparison Assay: The skulls were cut from 3-month-old mice, fixed with 4\% PFA for 1 hour at room temperature and decalcified with Formical-4 for 2 days, with Immunocal (Decal Chemical Corporation, Congers, NY) for 2 days, or with 0.1 M EDTA solution for 3 weeks. The decalcified skulls were embedded in O.C.T., sectioned, and stained with LacZ solution as described above.

Temperature Assay: The skulls were removed from 3month-old mice, cut in half, fixed with 4\% PFA for 1 hour at room temperature and decalcified with the $0.1 \mathrm{M}$ EDTA solu- tion at RT, $37^{\circ} \mathrm{C}, 42^{\circ} \mathrm{C}$ or $50^{\circ} \mathrm{C}$, as follows: first, the skull specimens of different ages were placed in one-liter bottles filled with $0.1 \mathrm{M}$ EDTA. The bottles containing skulls were then placed in the multi-stirrer water bath (Lab-line, Model 1286, Melrose Park, IL) and filled with water warmed at a desired temperature with a constant mixing of the demineralization agent. The demineralization of the mouse skulls of different ages was performed one temperature at a time. As an alternate method, the skull specimens were placed in a 50 $\mathrm{ml}$ tube filled with $0.1 \mathrm{M}$ EDTA. The $50 \mathrm{ml}$ tube containing skull specimens was placed and rotated in a temperaturecontrolled hybridization oven (Little Shot II, Boekel Scientific, Feasterville, PA). The skull specimens were $\mathrm{x}$-rayed (model MX20, Faxitron x-ray Corporation, Wheeling, IL) daily at an optimized setting of $20 \mathrm{KV} \mathrm{X} 45$ seconds to monitor the progression of the demineralization process.

Von Kossa Staining: The frozen sections from the decalcified skulls were prepared as described above, and the completion of the demineralization process was confirmed by incubating the slides in $5 \%$ silver nitrate solution for 1 hour. They were then rinsed with distilled water three times and counterstained with Nuclear Fast Red solution. The slides were then dehydrated first in $95 \%$, and then in $100 \%$ alcohol, mounted with a xylene-based mounting medium, and the images were photographed.

Reverse Transcription- PCR: The skulls were cut from 3-month-old mice, fixed, decalcified at $37^{\circ} \mathrm{C}, 42^{\circ} \mathrm{C}$ or $50^{\circ} \mathrm{C}$, and cut by a cryostat into slides of $12 \mu \mathrm{m}$ thickness as described above. Odontoblasts were taken directly from the slides of the frozen tooth sections using toothpicks, and the total RNA was prepared using TRIZOL (Invitrogen). The RNA specimens were subjected to first strand cDNA synthesis using the Superscript first strand synthesis system, and RT-PCR (Invitrogen) was performed using GAPDH standard primers (Forward-CCATCACCATCTTCCAGGAG and Reverse-GCATGGACTGTGGT CATGAG). All PCR reactions were carried out in a PerkinElmer gene PCR system 600 (PerkinElmer, Waltham, MA).

\section{RESULTS}

Evaluation of fixatives and fixation time on $\beta$ galactosidase activity: The effects of different fixatives on $\beta$ galactosidase activity in soft tissues were reported earlier [17], however there are no such reports about the effects of different fixatives on hard tissues such as teeth. To examine which fixative agent is suitable to analyze $\beta$-galactosidase activity in tooth sections, we first compared the effects of 1 hour fixation by $0.25 \%$ glutaraldehyde, $4 \%$ PFA, zinc formalin, and formalin. As shown in Fig. (1), we could detect similar levels of $\beta$-galactosidase activity in the odontoblasts of the incisors from the skulls fixed with different fixatives, indicating that treatment with these agents retained the enzyme activity at a similar level. To further investigate the optimum fixation time for analyzing $\beta$-galactosidase activity in teeth, we post-fixed the tooth section with $4 \%$ PFA for different periods of times. All the time periods tested, except for the 2 hour time period, yielded a strong signal for $B$ galactosidase activity (Fig. 2).

EDTA based demineralization maintains $\beta$-galactosidase activity: The acidity of demineralization agents has been 

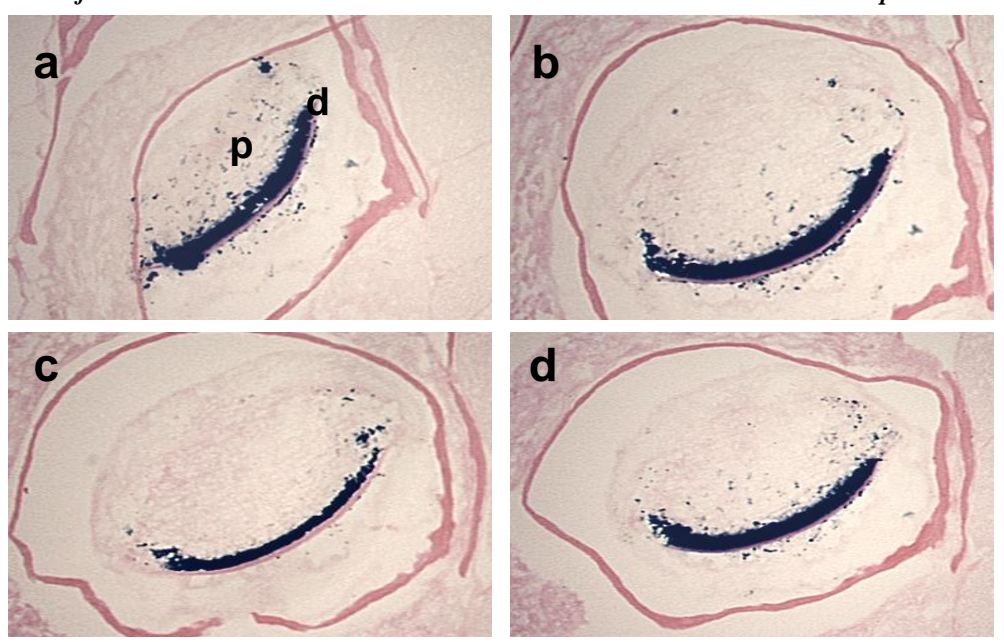

Fig. (1). Effects of fixative solutions on B-galactosidase activity.

The cross sections of the mandibular incisors of the 3-month-old Dspp-LacZ mouse skulls fixed with either 0.25\% Glutaraldehyde (a), 4\% paraformaldehyde (b), Zinc Formalin (c), or 10\% Formalin (d), for $1 \mathrm{~h}$ at RT, decalcified in 0.1\% EDTA for 3 weeks and then stained for Bgalactosidase activity. In all the sections, clear staining was observed in the odontoblast layer and some positive spots were detected in the tooth pulp. d, dentin; p, pulp.
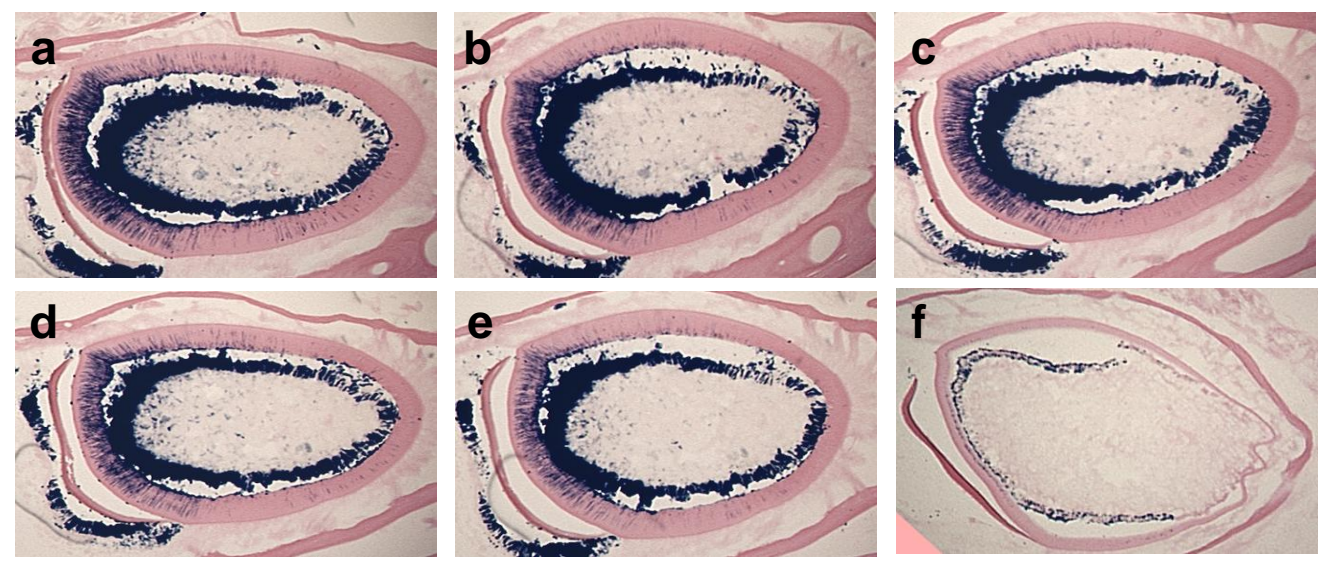

Fig. (2). Effect of fixation period for B-galactosidase activity.

The cross-sections of the mandibular incisors from 3-month-old Dspp-lacZ mice show different levels of $\beta$-galactosidase activity. The sections were post-fixed with $4 \%$ paraformaldehyde for 0 minutes (a), 2 minutes (b), 5 minutes (c), 10 minutes (d), 30 minutes (e), or 2 hours (f). Note the absence of the $\beta$-galactosidase activity in tooth sections post-fixed for 2 hours.
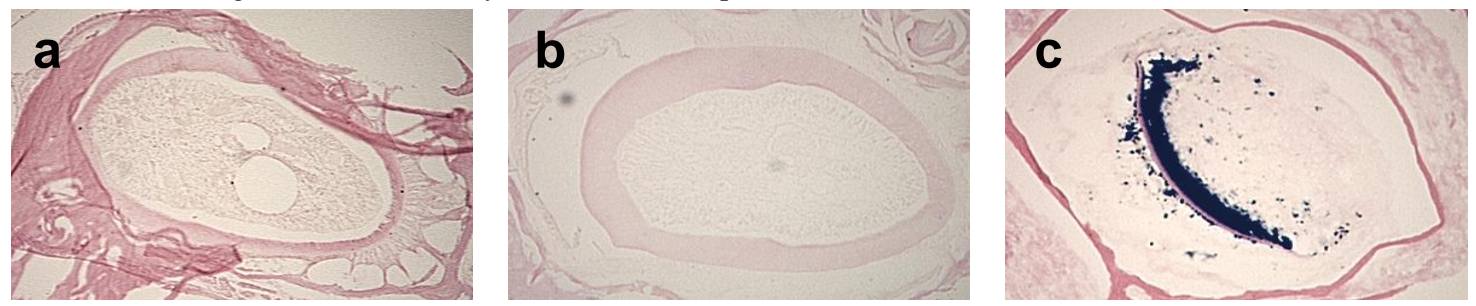

Fig. (3). The choice of the decalcifier reagent affects B-galactosidase activity. The 3-month-old Dspp-lacZ mouse skulls were fixed with $4 \%$ PFA and decalcified with either Formical-4 (a), Immunocal (b), or 0.1M EDTA in PBS (c). Absence of blue staining in the odontoblasts of sections (a) and (b) indicates a lack of B-galactosidase enzyme activity. Only the incisor sections from the skulls decalcified with the EDTA- based demineralization agent preserved the activity, as indicated by the blue product of the $\beta$-galactosidase substrate (c).

reported to affect the stability of proteins, enzyme activities and tissue integrity [8]. Therefore, we analyzed the effects of various demineralization reagents on the $\beta$-galactosidase activity. We fixed the skulls from 3-month-old Dspp-LacZ mice with 4\% PFA and then decalcified them in Formical-4 and Immunocal solution, both of which are formic acidbased fixative decalcifiers. We then prepared the frozen sections, stained them with LacZ solution and compared the Bgalactosidase activity with the sections from the skulls that were fixed by $4 \%$ PFA and decalcified with $0.1 \mathrm{M}$ EDTA. Only the tooth sections from the skulls treated with EDTAbased decalcifiers preserved the enzyme activity, as shown by the strong blue staining in the odontoblasts in Fig. (3c).

Since moderate increase in incubation temperature could shorten the demineralization process time period for the analysis of $\beta$-galactosidase activity, we tested the effects of elevated temperatures during the demineralization process using $0.1 \mathrm{M}$ EDTA as a decalcifier. The degree of opacity 


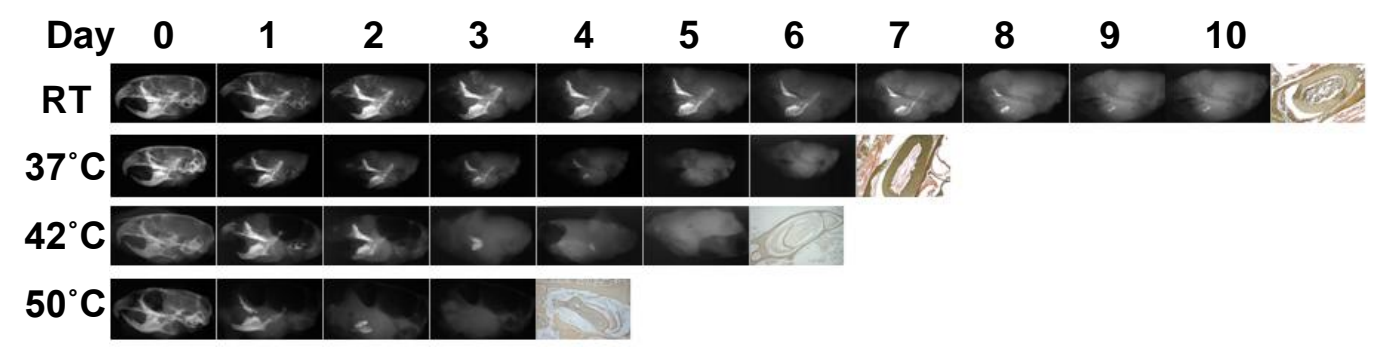

Fig. (4). The rapid demineralization at higher temperature.

Soft x-ray images of the mouse skulls fixed with $4 \%$ PFA for 1 hour during the demineralization process at different temperatures; $\mathrm{RT}, 37^{\circ} \mathrm{C}$, $42^{\circ} \mathrm{C}$, and $50^{\circ} \mathrm{C}$ showing various degrees of tissue being decalcified at different time points, as evidenced by the steady decrease in radioopacity area. The far right panel in each row shows the incisor sections made from completely decalcified skull and stained with von Kossa to confirm complete demineralization, as indicated by the light brown precipitate. 0.1M EDTA is used as a demineralizeing agent for all of the skulls at indicated temperatures.
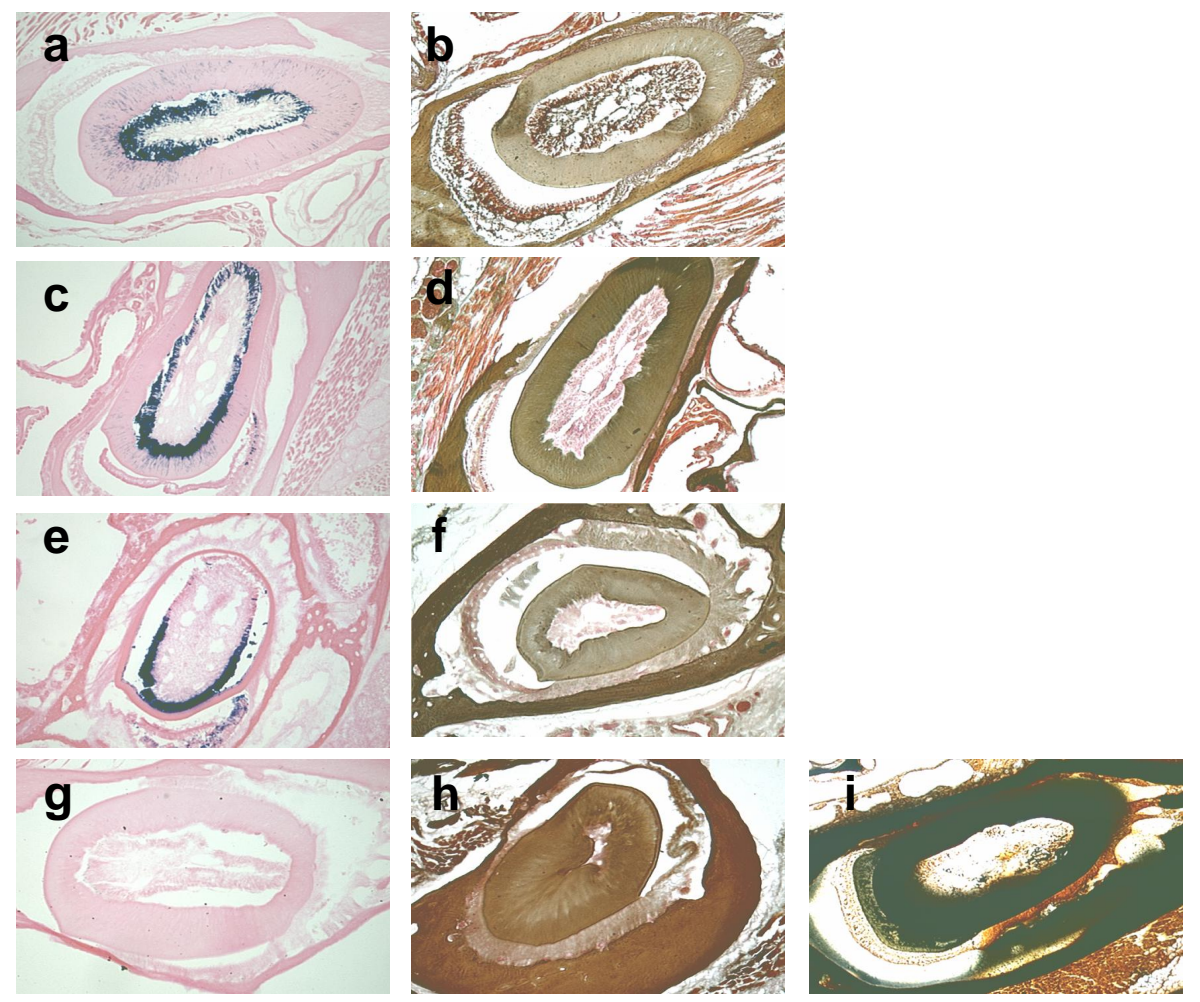

Fig. (5). The B-galactosidase activity is retained at $42^{\circ} \mathrm{C}$ but not at $50^{\circ} \mathrm{C}$.

ß-galactosidase and von Kossa staining of the cross-sections of 3-month-old mouse incisors decalcified at RT (a, b), $37^{\circ} \mathrm{C}(\mathrm{c}, \mathrm{d}), 42^{\circ} \mathrm{C}(\mathrm{e}, \mathrm{f})$, and $50^{\circ} \mathrm{C}(\mathrm{g}, \mathrm{h})$. The $\beta$-galactosidase enzyme is active in teeth decalcified at RT, $37^{\circ} \mathrm{C}$ and $42^{\circ} \mathrm{C}$, but not at $50^{\circ} \mathrm{C}$, as indicated by the blue staining. 0.1M EDTA is used as a demineralizing agent for all of the temperatures tested. The plastic section of the undecalcified incisor that is the same age as the control slide for von Kossa staining (i).

was well-correlated with the degree of skull demineralization. The undecalcified areas of the skulls appeared as radioopacity in the x-ray image. At RT, 10 days of incubation were required for complete demineralization, however just 6 , 5 , and 3 days were required at $37^{\circ} \mathrm{C}, 42^{\circ} \mathrm{C}$, and $50^{\circ} \mathrm{C}$, respectively (Fig. 4). Next, in order to test the effects of each temperature on the stability of $\beta$-galactosidase activity at the time of complete demineralization, we decalcified the skulls with 0.1M EDTA for a sufficient period of time, which was 10 days at RT, 6 days at $37^{\circ} \mathrm{C}, 5$ days at $42^{\circ} \mathrm{C}$, and 3 days at $50^{\circ} \mathrm{C}$, and then we analyzed the $\beta$-galactosidase enzyme activity in the sections. We found that the skulls decalcified at $37^{\circ} \mathrm{C}$ and $42^{\circ} \mathrm{C}$, but not at $50^{\circ} \mathrm{C}$, showed equivalent $\mathrm{B}$ galactosidase enzyme activity, although at $50^{\circ} \mathrm{C}$ the incubation time was the shortest (Fig. 5). The successful completion of the demineralization process was indicated by the light brown precipitate on tooth sections in Fig. ( $5 \mathbf{~ b , ~} \mathbf{d}, \mathbf{f}$ and h), as opposed to the dark brown calcium deposit shown in the undecalcified control tooth section (Fig. 5i).

Longer time required for demineralization of mouse skulls from older mice: Having demonstrated that we can achieve a rapid demineralization at $42^{\circ} \mathrm{C}$ with $0.1 \mathrm{M}$ EDTA, we then investigated the effects of aging on the time required for complete demineralization of the skulls. The time required for a complete demineralization of the skulls of 2week-old and 1-month-old mice was 3 to 4 days, whereas for 3 -month-old and 1-year-old mouse skulls it was 5 to 6 days (Fig. 6).

Elevated incubation temperature used for demineralization process did not affect stability of nucleic acids: To evaluate the effects of elevated temperatures on the stability 


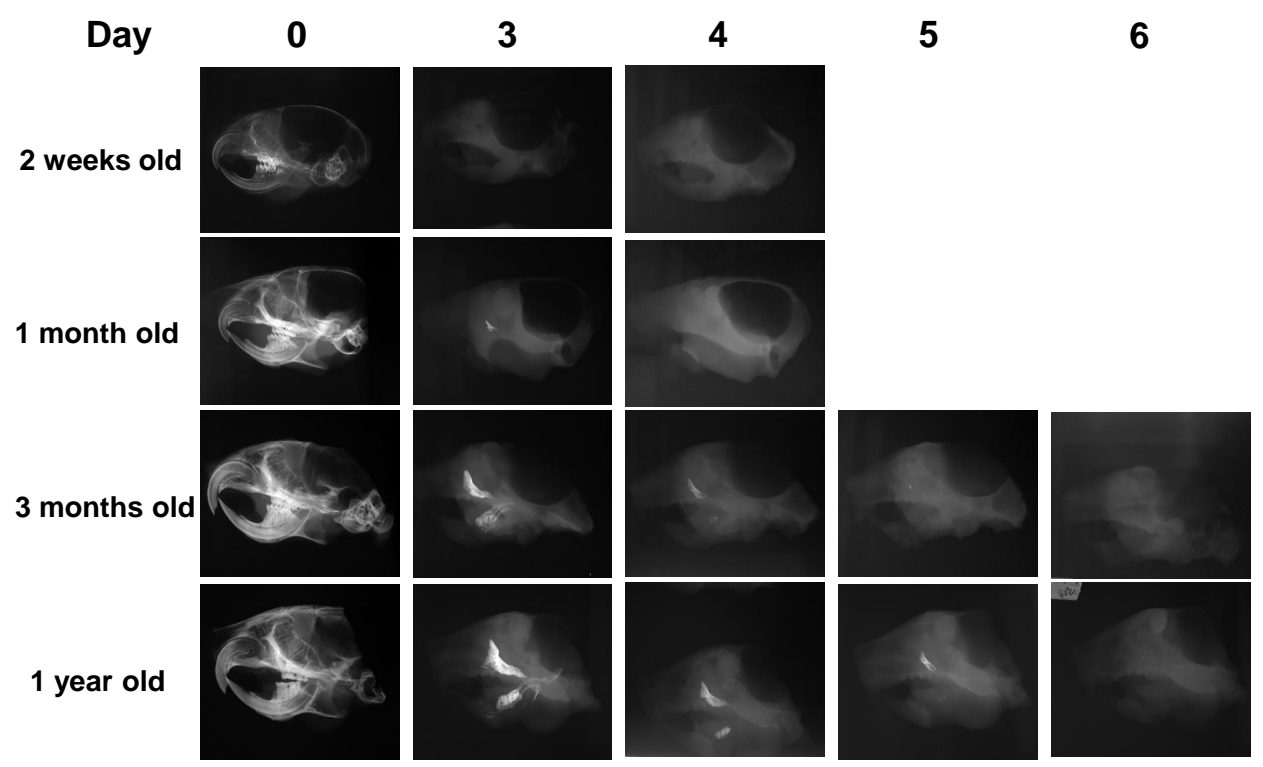

Fig. (6). Difference in the time required for accelerated demineralization of the skulls from the older mice.

Soft x-ray images showing the time required for complete demineralization of the skulls of mice of different ages subjected to the demineralization process at $42^{\circ} \mathrm{C}$ in $0.1 \mathrm{M}$ EDTA. Note that for complete demineralization, the skulls of both 2-week-old and 1-month-old mice required 3 to 4 days, while the skulls of 3-month-old and 1-year-old mice required 5 to 6 days. 0.1M EDTA was used as a demineralizing agent for all of the temperatures tested.

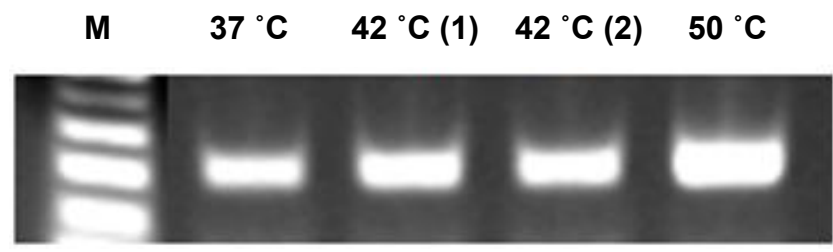

Fig. (7). Demineralization at higher temperature does not affect nucleic acid stability.

RT-PCR assay of Gapdh mRNA extracted from the slides of frozen tooth sections made from skulls decalcified at different temperatures; $\mathrm{RT}, 37^{\circ} \mathrm{C}, 42^{\circ} \mathrm{C}$, and $50^{\circ} \mathrm{C}$. The amplification of RNA confirms the stability of nucleic acids exposed to $50^{\circ} \mathrm{C}$ temperature during the demineralization process.

of nucleic acids, we performed RT-PCR using mRNA extracted from the tooth sections. The amplification of Gapdh mRNA transcripts at $37^{\circ} \mathrm{C}, 42^{\circ} \mathrm{C}$ or $50^{\circ} \mathrm{C}$ all showed similar levels (Fig. 7).

\section{DISCUSSION}

We set out to optimize the demineralization method in order to make it shorter and safer for histological analysis of mouse teeth. In the process of this optimization, we addressed some of the key issues related to the effects of the decalcifiers and fixatives used for preparing the mouse skull specimen. Our study indicates that the demineralization of mouse skulls at $42^{\circ} \mathrm{C}$ using $0.1 \mathrm{M}$ EDTA can significantly shorten the time required for complete demineralization, while also retaining sufficient $\beta$-galactosidase activity.

DSPP, a key dentin extracellular matrix protein secreted by odontoblasts, plays a crucial role in the mineralization of predentin to form mature dentin [18-21]. We previously reported the isolation and characterization of the murine Dspp gene [22] and the validation of its promoter sequence [16]. The Dspp-LacZ transgenic mice used in the present study to display spatial and temporal expression patterns similar to endogenous DSPP expression profiles [16]. In these mice, the LacZ gene, which is placed under the DSPP promoter sequence, is expressed as early as embryonic day 17.5 (E17.5) in preameloblasts and odontoblasts, and at E18.5 in molars. Its expression in preameloblasts is transient, whereas it stays robust in odontoblasts throughout tooth development. Because of this expression profile, the tooth specimens from these mice are ideal for testing the effects of decalcifiers, fixatives and incubation conditions on the stability of $\beta$ galactosidase activity. However, because the LacZ gene, which encodes $\beta$-galactosidase, has been widely used as a reporter gene to analyze the expression of a gene of interest, the demineralization protocol that we have optimized in the current study can be applied to other transgenic mouse models expressing $\beta$-galactosidase in teeth and bones.

We first verified the effects of various fixatives and the fixation time on the stability of the $\beta$-galactosidase enzyme in the tooth sections. We tested $0.25 \%$ glutaraldehyde, $4 \%$ PFA, zinc formalin and formalin for their effects, and found that all of them work well as fixatives to analyze $\beta$ galactosidase activity in the tooth sections (Fig. 1). As for the fixation time, we found that post-incubation of the skulls with $4 \%$ PFA for up to an hour did not have any adverse effects on $B$-galactosidase activity. However, extending the 
incubation time to 2 hours adversely affected the enzyme activity (Fig. 2). As previously reported [17], LacZ enzymatic activity in kidney tissue was also retained during a 1hour incubation time with 4\% PFA, but not during a longer period of time.

Next, we tested the acid-based demineralization reagents, Formical-4 and Immunocal, in order to analyze their effects on B-galactosidase activity. As you can see in Fig. (3), it is clear that $0.1 \%$ EDTA, but not the acid-based demineralization reagents, maintained $\beta$-galactosidase enzyme activity after complete demineralization (Fig. 3). Chelating agents such as EDTA can bind to calcium and other ions and remove them from mineralized tissue. This reaction occurs gently, and enzymatic activity can therefore be retained during demineralization. In contrast, long-term exposure to acidic conditions could potentially destroy enzymatic activity such as $\beta$-galactosidase. Another possibility is that, because Formical-4 and Immunocal contain fixatives, Bgalactosidase may be over-fixed and thus result in a lack of enzymatic activity. As shown in Fig. (4), we then explored the potential for shortening the demineralization process by increasing the temperature during demineralization, since it has already been reported that bone demineralization was accelerated by microwave treatment $[10,11]$. Our data indicated that incubation of mouse skulls with 0.1M EDTA at $42^{\circ} \mathrm{C}$ results in demineralization that is 2 -fold faster than incubation at room temperature. Our data also revealed that, although an incubation temperature of $50^{\circ} \mathrm{C}$ can achieve demineralization the shortest incubation time, it adversely affects the enzyme activity (Fig. 5). These data suggest that incubation at $42^{\circ} \mathrm{C}$ is most useful for analysis of enzymatic activity in decalcified teeth. Moreover, as shown in Fig. (6), 6 days of incubation with $0.1 \mathrm{M}$ EDTA at $42^{\circ} \mathrm{C}$ was sufficient for complete demineralization of 1-year-old mouse teeth. These observations suggest that any specimens can be demineralized by incubation with $0.1 \mathrm{M}$ EDTA at $42^{\circ} \mathrm{C}$ for 6 days.

To assess the effects of elevated temperatures on the stability of nucleic acids, we extracted total RNA from the tooth sections of the skulls subjected to different temperatures for the demineralization process, and performed RTPCR analysis. The amplification of Gapdh mRNA transcripts at $37^{\circ} \mathrm{C}, 42^{\circ} \mathrm{C}$ or $50^{\circ} \mathrm{C}$ showed similar levels, indicating that a higher temperature had no affect on the stability of nucleic acids (Fig. 7).

In summary, we have optimized the conditions for rapid demineralization of mouse skulls, which significantly shortens the time required for complete demineralization but does not affect the enzyme activity or nucleic acids in the tooth sections. We recommend 0.1M EDTA as a safe decalcifier, to be used at $42^{\circ} \mathrm{C}$ for successful demineralization of mouse skulls. These conditions could be widely applied for the enzymatic and immunohistochemical analysis of other proteins in hard tissues. Moreover, rapid demineralization using this method will promote quicker analysis of genes and proteins implicated in tooth and bone diseases.

\section{ACKNOWLEDGEMENTS}

We would like to thank Dr. Taduru Sreenath for his helpful suggestions during the course of this project. We also would like to thank Drs. Marian Young and Larry Fisher for critical reading of the manuscript, and Shelagh Powers for expert editorial corrections. This work was supported by funds from the Division of Intramural Research of the National Institute of Dental and Craniofacial Research.

\section{REFERENCES}

[1] Shibata Y, Fujita S, Takahashi H, Yamaguchi A, Koji T. Assessment of decalcifying protocols for detection of specific RNA by non-radioactive in situ hybridization in calcified tissues. Histochem Cell Biol. 2000; 113:153-9.

[2] Yamamoto-Fukuda T, Shibata Y, Hishikawa Y, et al. Effects of various demineralization protocols on detection of DNA strand breaks by terminal dUTP nick end labeling. J Histochem 2000; 32: 697-702.

[3] McGee MD, Nanci A, Landis WJ, Gotoh Y, Gerstenfeld LC, Glimcher MJ. Effects of fixation and demineralization on the retention of bone phosphoprotein and other matrix components as evaluated by biochemical analyses and quantitative immunocytochemistry. J Bone Mineral Res 1991; 6(9): 937-45.

[4] Warshawsky H, Moore G. A technique for the fixation and decalcification of rat incisors for electron microscopy. J Histochem and Cytochem 1967; 15(9): 542-9.

[5] Bourque WT, Gross M, Hall BK. A Histological processing technique that preserves the integrity of calcified Tissues (bone, Enamel), Yolky amphibian embryos, and growth factor antigens in skeletal tissue. J Histochem and Cytochem 1993; 41(9): 1429-34.

[6] Hume WJ, Keat S. Immunohistological optimization of detection of Bromodeoxyuridine-labeled cells in decalcified tissue. J Histochem Cytochem 1990; 38(4): 509-13.

[7] Oshiro T, Shibasaki Y, John MT, Sasaki T. Immunolocalization of vacuolar-type $\mathrm{H}^{+}$-ATPase, Cathepsin K, Matrix Metalloproteinase9, and receptor activator of NFkB ligand in Odontoclasts during physiological root resorption of human deciduous teeth. Anatomical Record 2001; 264: 305-11.

[8] Iwasaki Y, Hara Y, Koji T, Shibata Y, Nakane PK, Kato I. Differential expression of IFN- $¥$, IL-4, IL-10, and IL-1ß mRNA's in decalcified tissue sections of mouse lipopolysaccharide-induced periodontitis mandibles assessed by in situ hybridization. Histochem Cell Biol 1998; 109: 339-47.

[9] Sreenath TL, Cho A, Thyagarajan T, Kulkarni AB. Odontoblastspecific expression of Cre recombinase successfully deletes gene segments flanked by loxP sites in mouse teeth. Genesis 2003; 35: 94-9.

[10] Pitol DL, Caetano FH, Lunardi LO. Microwave-induced fast decalcification of rat bone for electron microscopic analysis: an ultrastructural and cytochemical study. Bradz Dent J 2007; 18(2): 1537.

[11] Ekuni D, Firth J, Putnins E. RNA integrity and in situ RT-PCR in dento-alveolar tissues after microwave accelerated demineralization. Arch Oral Bio 2006; 51:164-9.

[12] Vongsavan N, Matthews B, Harrison K. Decalcification of teeth in a microwave oven. Histochem J 1990; 22: 377-80.

[13] Serebriiskii IG, Golemis EA. Uses of lacZ to study gene function: evaluation of $\beta$-galactosidase assays employed in the yeast twohybrid system. Anal Biochem 2000; 285:1-15.

[14] Spergel DJ, Kruth U, Shimshek DR, Sprengel R, Seeburg PH. Using reporter gene to label selected neuronal populations in transgenic mice for gene promoter, anatomical, and physiological studies. Prog in neurobiol 2001; 63: 673-86.

[15] Lobe C, Koop KE, Dreppner W, Lomeli H, Gertsenstein M, Nagy A. Z/AP, a double reporter for Cre-mediated recombination. Dev Bio 1991; 208: 281-92.

[16] Sreenath TL, Cho A, MacDougall M, Kulkarni AB. Spatial and temporal activity of the dentin sialophosphoprotein gene promoter: differential regulation in odontoblasts and ameloblasts. Int J Dev Biol 1999; 43: 509-16.

[17] Ma W, Rogers K, Zbar B, Schmidt L. Effects of different fixatives on B-galactosidase activity. J Histochem and Cytochem 2002; 50(10): 1421-24

[18] Butler WT, Ritchie HH. The nature and functional significance of dentin extracellular matrix proteins. Int J Dev Biol 1995; 39: 16979. 
[19] Sreenath T, Thyagarajan T, Hall B, et al. Dentin sialophosphoprotein knockout mouse teeth display widened predentin zone and develop defective dentin mineralization similar to human dentinogenesis imperfecta type III. J Biol Chem 2003; 278: 24874-80.

[20] Suzuki S, Sreenath T, Haruyama N, et al. Dentin sialoprotein and dentin phosphoprotein have distinct roles in dentin mineralization. Matrix Biol 2009; 28(4): 221-9.
[21] Haruyama N, Sreenath TL, Suzuki S, et al. Genetic evidence for key roles of decorin and biglycan in dentin. Matrix Biol 2009; 28(3): 129-36.

[22] Feng JQ, Luan X, Wallace J, et al. Genomic organization, chromosomal mapping, and promoter analysis of the mouse dentin sialophosphoprotein (Dspp) gene, which codes for both dentin sialoprotein and dentin phosphoprotein. J Biol Chem 1998; 273: 945764.

Received: July 21, 2010

(C) Cho et al.; Licensee Bentham Open.

This is an open access article licensed under the terms of the Creative Commons Attribution Non-Commercial License (http://creativecommons.org/licenses/by-nc/3.0/) which permits unrestricted, non-commercial use, distribution and reproduction in any medium, provided the work is properly cited. 